\title{
Performance of Indonesian EFL Learners and Thai EFL Learners on Compliment Responses in English
}

\author{
Payung Cedar (Corresponding author) \\ Faculty of Humanities, Naresuan University University, Phitsanulook 65000, Thailand \\ E-mail: payungp@nu.ac.th \\ Asep Setiadi \\ Faculty of Humanities, Naresuan University, Phitsanulook 65000, Thailand \\ E-mail: asepsetiadi@hotmail.com
}

Received: 10-08-2016

Published: 10-12-2016
Accepted: 16-10-2016

doi:10.7575/aiac.ijalel.v.5n.7p.63
Advance Access Published: November 2016

URL: http://dx.doi.org/10.7575/aiac.ijalel.v.5n.7p.63

\begin{abstract}
Cultures carry norms and expectations on how speech acts are performed. On the other hand, responding to compliments is challenging in nature for not only it involves an internal conflict, but also is subject to cultures and other factors. This study investigated how Indonesian and Thai English major students respond to English compliments and the effect of compliment topics in their CRs (Compliment Responses). The study made use of a set of DCT questionnaire distributed to 35 Indonesian and 35 Thai university students majoring in English in their first year. Employing Tran's (2007) Continua of CRs, the findings demonstrated significant differences in the CRs between Indonesians and Thais triggered by cultural differences of the two groups of subjects and different preferences of compliment topics. In general, Indonesians were found to be more prone to deny compliments while Thais tended to accept compliments. In relation to compliment topics, Indonesians were observed to be most positive towards compliments on ability and most negative towards compliments on possession. On the other hand, Thais tended to be most positive towards possession and most negative towards appearance. In addition, the results of the study also offered methodological and pedagogical implications.
\end{abstract}

Keywords: intercultural communication, compliments, compliment responses, EFL, compliment topics

\section{Introduction}

Intercultural communication, carried out by members of different communities or linguistic backgrounds, is a complex event. The action of using a language in communication is not only aimed at conveying information but also at carrying certain purposes that are often realized differently across speech communities for cultures carry varying expectations and norms on how linguistic signs should be used and interpreted (Bowe \& Martin, 2014). Interlanguage speakers, or non-native speakers, in such interactions have a tendency to carry a certain degree of conventions from their L1 to their L2 production that potentially make listeners fail to understand what others mean by their utterances, or experience 'pragmatic failure', which can lead to a more serious 'communication breakdown'. To be an effective communicator, one needs to possess pragmatic competence, that is, the ability to communicate effectively and it involves knowledge beyond the level of grammar (Thomas, 1983). The competence is pivotal, especially for EFL learners to be able to set aside their native cultural conventions and to perform speech acts in the target language properly.

However, the trend has changed nowadays due to the unprecedented spread of English marked with the increased usage of English as a 'lingua franca'. English is broadly used in interactions, not only between native and non-native speakers, but prominently among non-natives. According to (Crystal, 2003, p. 2), nowadays English belongs to everyone who learns and speaks it and so everyone 'has the right to use it in the way they want' (ibid). As a consequence, this comes as an encouragement to non-native speakers of English to carry certain features of their native languages and cultures in their intercultural communication with other non-native speakers of the language. Therefore, it suggests that today being competent at the English native speakers' pragmatic norms is no longer mandatory and it raises the importance of having knowledge of other cultures involved in such communication, especially regarding how speech acts are carried out.

Among various types of speech acts that draw attention of researchers in the field of pragmatics and intercultural communication are compliments and compliment responses (CRs). 'A compliment is a speech act which explicitly or implicitly bestows credit upon the addressee' (Hobbs, 2003, p. 249). Compliments maintain social harmony and social interaction (Cedar, 2006; Chiang \& Pochtrager, 1993). As an act to indicate positive politeness (Brown and Levinson, 1978, 1987 in Yu, 2005), acceptable responses to compliments are expected to ensue from the complimentee. CRs, thus, are expressions or acts produced as a response to compliments given by the speaker. Despite its seemingly simple 
definition, responding to compliments is complicated and challenging by nature, given the fact that it is most likely to involve an internal conflict, in the self of the complimentee, of whether to agree or to disagree with the compliment (Gajaseni, 1994). To accept a compliment, Gajaseni suggested, means one is at risk of being seen as immodest or conceited and, on the other hand, to reject a compliment one is at risk of violating the norm of politeness. Consequently, the aforementioned role and nature of compliments and CRs bolster the importance of studies to be carried out. In addition, investigations in the field seem to be pivotal, especially in communication among members of different cultures, considering that, similar to other speech acts, they are subject to cultural differences (Lorenzo-Dus, 2001; Golato, 2002; Yu, 2005; Al Falasi, 2007; Chen \& Rau, 2011), even more when these differences are intricately blended with other variables such as compliment topics (Boonkongsaen, 2011; Chen \& Boonkongsaen, 2012; Allami \& Montazeri, 2012; Katsuta, 2012).

In relation to culture, Cedar's (2006) study with Thai learners of English living in the US and native American speakers revealed that Thai learners of English living in the US showed different patterns of CRs from the native Americans. Although both groups gave acceptance and positive elaboration most frequently, Americans showed a higher frequency. She also found responses peculiar to one another; Americans returned the compliments and Thais smiled. Regarding compliment topics, Chiang and Pochtrager (1993) revealed that Americans were most positive in responding to compliments on ability and most negative on possessions while the Chinese participants were most positive concerning possessions and most negative on appearance.

Finally, it has become apparent that CRs have an important role, complex nature, and vast dimensions in communication across speech communities, due to which they deserve attentions from researchers. Despite the large number of studies having been conducted in English CRs, most of them concerned comparing the performance of the speech act between native and non-native speakers. In the meantime, it leaves a gap for such studies among non-native speakers of English. Therefore, this study is an endeavor to fill the space in the field of English CRs among non-native speakers by comparing CR strategies of Indonesian students and those of Thai students majoring in English using CR continuum formula proposed by Tran (2007)

Indonesia and Thailand are two ASEAN countries that are actively supporting each other in a number of areas, e.g. education through exchanging students and scholars. Despite having many things in common such as cultural heritages, the people characters, and role of English, including their speech behaviors - typical of eastern cultures which are inclined to show togetherness and modesty, the two countries are different in their language system in both spoken and written language and in the fact that Indonesia is a multilingual country, and Thailand is more restricted to linguistic variations. This implies different cultural backgrounds and value systems. Due to these differences, the study is expected to bring more perspectives in understanding intercultural communication in general and particularly between Indonesians and Thais so that possible misunderstanding triggered by these cultural differences can be attenuated and better communication can be established. Realizing the importance of having profound knowledge on speech act performances across speech communities of non-native speakers, e.g. Indonesians and Thais, the study will be of a great benefit in helping learners and other parties in interest coping with sociocultural barriers in their intercultural communication. In a more practical way, it should be useful as an applicable basis for classroom teaching and learning of English for communication in the world of EFL. Furthermore, the findings of this research will make the importance of intercultural knowledge clearer for interlanguage learners so their awareness of cultural differences will improve. Also, the results can enrich the literature for further studies in the relevant areas.

The current study is aimed at gaining insights into cross-cultural understanding of Indonesians and Thais in terms of CRs in general and in relation to compliment topics. It is designed to answer the following questions.

1) How do Indonesian students and Thai students majoring in English respond to compliments in English?

2) What are the differences between $C R$ strategies used by the Indonesian students and those used by the Thai students, majoring in English, under the variables of compliment topics?

\section{Theoretical Background}

\subsection{Interlanguage Pragmatics}

The current study deals with the performance of speech acts of CRs in English in particular situations and involves two culturally diverse groups of English learners. As a consequence, this study falls into the field of Interlanguage Pragmatics (ILP). Interlanguage pragmatics is a relatively new discipline in linguistics that emerges from a mix of two domains, pragmatics and interlanguage. Pragmatics is the scientific study of all aspects of linguistic behavior, which deals with meaning-in-context (Bardovi-Harlig, 2010). In relation to interlanguage, Kasper \& Rose (2002), in Schauer (2009), describe that it deals with the comprehension and act performance of nonnative speakers in a target language, as well as with the development of L2 learners' ability to understand and perform action in a target language. In other words, it is the study of the use of a second language by learners. Studies in ILP mainly attempt to improve learners' pragmatic competence. While ILP is originally a broad field, the scope of studies in this field is often narrowed down to the investigations of speech act performance by language learners.

\subsection{Pragmatic Competence}

Similar to other ILP studies, the current research tries to promote the importance of having knowledge of speech act performances, e.g. compliment responses, across speech communities or cultures. This notion is crucial for the enhancement of learners' pragmatic competence. It has been widely believed that language carries certain cultural 
values and norms of the society where the language is spoken in the form of beliefs and expectations in the use of language for communication shared by its native speakers. A culture has its own pragmatic conventions agreed on by its members in how to perform thoughts and intentions in their language. Therefore, it is important for L2 learners to be familiar with the pragmatic norms and rules of the target language and culture (Schauer, 2009). They need to have access to some kind of knowledge shared by native speakers of the target language to be able to express what they intend to communicate and to be thus understood. In other words, L2 learners need to possess a certain degree of pragmatic competence of the target language to be able to take part in communication appropriately. Schauer describes pragmatic competence concerning 'appropriate ways of performing speech acts according to the social context' (2009, $\mathrm{p}$. 37). In interlanguage context, the difference lies in the conventions accounted as the standard, i.e. the native speakers'. L2 learners' pragmatic competence can be described in terms of the degree of closeness between their pragmatic behavior and that of native speakers of the target language (Dippold, 2008). Pragmatic competence is commonly described to have two dimensions: pragmalinguistic and sociopragmatic. The former refers to 'the knowledge of forms and strategies to convey particular illocutions' and the latter, on the other hand, is associated with the ability to appropriately use 'these forms and strategies in a given context' (Leech 1983; Kasper and Roever 2005, cited in Dippold, 2008, p.131). Under this perspective, studies on compliment responses are more closely related to the second dimension of pragmatic competence.

\subsection{Leech's Politeness Theory}

Each culture maintains its own pragmatic conventions which are fully or partly unique to a particular speech community and should be obeyed by its members. In other words, members of a speech community are expected to show polite behavior in communication, that is, to speak or behave in such a way as to give benefit or value to the others involved in communication (Leech, 2014). Its unique nature results in the different politeness norms held by each culture or community. To account for this intricate nature of politeness, Leech (1983, in Leech, 2014) proposed principles in regard to politeness called 'Politeness Principles' (PP). Leech's principles consist of six maxims that include:

1) 'tact' maxim (minimizing cost to other; maximizing benefit to other)

2) 'generosity' maxim (minimizing benefit to self; maximizing cost to self)

3) 'approbation' maxim (minimizing dispraise of other; maximizing praise of other)

4) 'modesty' maxim (minimizing praise of self; maximizing dispraise of self)

5) 'agreement' maxim (minimizing disagreement between self and other; maximizing agreement between self and other)

6) 'sympathy' maxim (minimizing antipathy between self and other; maximizing sympathy between self and other) (Watts, 2003, pp. 66-67)

Under this theory, it is argued that different speech communities may preserve different maxims or show stronger preferences on certain maxims than the others. In compliment responses, for example, some groups may prefer to show acceptance to compliments and thus are likely to practice the agreement maxim. In contrast, some other groups may be more inclined to show modesty in their responses to compliments. While the Politeness Principle theory does help in explaining the notion of politeness, there are some criticisms, maintaining that two maxims may conflict each other. Regarding this case, Leech added that when two maxims come into conflict the more 'powerful' maxim takes priority and it may vary from one culture to another (Katsuta, 2012).

\subsection{Compliments and Compliment Responses}

Compliment and compliment responses are speech acts relatively common in daily practice of using language. Compliments are an act mainly deemed favorable for it is typically performed to make the addressee feel good through positive words or utterances upon him/her (Lewandowska-Tomaszczyk, 1989). According to Hobbs, 'a compliment is a speech act which explicitly or implicitly bestows credit upon the addressee' (2003, p. 249). In the speech act theory, compliments belong to the category of 'expressive' in Searle' (1969) terminology, that is, the speech act aims to express a psychological state and thus is generally understood as 'phatic communion' (Senft, 2009), an utterance primarily produced to fulfill a social function.

Compliment responses, on the other hand, are acts given as responses to previously-indicated compliments. The presence of responses is not less important than the preceding act without which the desired aim of compliments can hardly be achieved and, instead, offence may arise. Brown and Levinson (1978 in Yu, 2005, p. 94) claim that 'the act of complimenting can also be seen as a kind of positive politeness strategy' and thus appropriate responses to compliments becomes essential. While providing acceptable responses to compliments is commonly thought of as necessary, it is nonetheless internally complicated for it can pose problems to the complimentee as to how to carry out the act. Pomerantz (1978) notes that responding to a compliment places the speaker in a 'dilemma' whether to agree with or reject the compliment (cited in Herbert, 1989). It is said so because each choice carries consequences for the speaker. Gajaseni (1994) suggests that to accept a compliment means one is at risk of being seen as immodest or conceited. On the other hand, to reject a compliment one is at risk of violating the norm of politeness.

\subsection{Tran's CRs Continua}

The investigation of CRs in this study made use of the adapted version of Tran's CR Continua. Tran (2007), in her investigation of compliment responses of Australian and Vietnamese, developed a new framework of compliment response strategies. She proposed two continua of compliment strategies consisting of a continuum of CR strategies 
from acceptance to denial strategies and a continuum of avoidance strategies. The underlying motive of the new framework was the inability of the available frameworks to fully account for the data in her study. Another reason is the idea that CR strategies are not supposed to be separate but connect with one another and form continuum (p. 7). As mentioned earlier, complimentee is often in the dilemma of whether to agree with the complimenter by accepting the complimentary force or to disagree with the complimenter to avoid self-praise (Pomerantz, 1978 cited in Tran, 2007). Pomerantz suggested that the complimentee often neither accepts nor rejects the compliment and prefers to use a strategy somewhere in between which can be captured by means of continua.

\subsection{A Brief Sociocultural Description of Indonesia and Thailand}

The current study investigates how Indonesian learners and Thai learners majoring in English respond to compliments. Indonesia and Thailand are two neighboring countries in the Southeast Asia which are often described to be culturally close in some ways yet different in other ways. Indonesia and Thailand share some common norms and values preserved in the society. Both countries hold collectivist culture typical of ASEAN countries in which group concerns are superior over individual goals (Barron, 2008; Watts, 2003). In this view, people are more inclined to show concerns about other people and value togetherness (Mills, 2011). In addition, maintaining social harmony is a desirable act expected from everyone to perform (Knutson, 2004; Novera, 2004). This notion is manifested in the way both Indonesians and Thais practice social interactions, for example, by concealing negative feelings, avoiding self-pride and confrontation, being modest and by holding careful ways of speaking. On the other hand, there are marked differences between Indonesia and Thailand. First, the two countries have different official languages which are distinctive in terms of oral, written and language structure systems. Moreover, hundreds of languages are currently spoken in Indonesia with the Indonesian language as the lingua franca while in Thailand, although there are a number of ethnic languages, Thais are expected to speak the Thai language in communication. Secondly, although Indonesia and Thailand are both multi-ethnic countries, there are a much higher number of ethnic groups living in Indonesia. Lastly, there are different dominant religions in Indonesia and Thailand, namely Islam and Buddhism respectively, which significantly contribute to the different social systems of the two societies.

\section{Method \\ 3.1 Subjects}

The current study involved 35 Indonesian students and 35 Thai students majoring in English. They were the first-year students of the English Language Education Major of a university in Indonesia and of the English Major of a university in Thailand respectively. The Thai group were drawn from a population of 56 students and selected upon their willingness to take part in an Oxford Placement Test equivalent and the data collection of the study. Following the Common European Framework of Reference (CEFR) of languages, 20 students were in the A2, 13 students in the B1, and 2 students in the B2 of English proficiency levels. Meanwhile, the Indonesian group were taken from a total of 68 students joining the Oxford Placement Test equivalent and the data collection. They were selected based on their English proficiency levels to be equal to those of the Thai group. Confidentiality measures were taken to maintain the subjects' privacy.

\subsection{Instrument}

The data in this study were collected using a questionnaire named Discourse Completion Task (DCT). In this context, a DCT is a set of tasks 'where subjects are presented with a situation in which a compliment (or a CR) is believed to be the next relevant action' (Golato, 2005, p. 12). It was used to collect the data since, Golato (2005) contends, it allows the researcher to control for certain variables and features of the situation and to quickly gather large amounts of data. In addition, the DCT suited the current study's aim, gaining insights into socio-culturally acceptable responses to compliments in both cultures, for it measures the subjects' culturally ideal perceptions and has been commonly used in interlanguage and cross-cultural pragmatics research (Félix-Brasdefer, 2010). The DCT employed in this study was a modified version of DCTs used in a number of previous studies (Chen \& Rau, 2011; Chiang \& Pochtrager, 1993; Sari, 2009).

The DCT was composed of two parts: instructions and the tasks that learners needed to accomplish. The first part consisted of the description of the DCT and the subjects' personal information and consent upon their willingness in taking part in the study. The second part comprised incomplete discourse sequences of 12 complimenting scenarios to which subjects were required to respond. The DCT was written in English yet the instructions were made available in two languages, English and either Indonesian Language or Thai, to avoid misunderstanding. The situations in the DCT varied in terms of topics that included ability/accomplishments $(1,6,7,11)$, appearance $(2,4,8,12)$, and possessions $(3,5,9,10)$ (Chiang \& Pochtrager, 1993; Ibrahim \& Riyanto, 2004).

To maintain the validity of the instrument, expert judgment was used involving two English instructors native to Indonesian Language and Thai respectively and one English native speaker. The index of Item Objective Congruence (IOC) (Rovinelli \& Hambleton, 1976) was also applied to inquire into the instrument relevance to the expected output. Then, the DCT was analyzed and revised based on the experts' and advisor's suggestions. On the other hand, the reliability of the DCT was achieved through a pilot study conducted with 30 first-year students of English Language and Literature major in Indonesia and 29 first-year students of English Education in Thailand. This procedure aimed to check its appropriateness, content relevance, item comprehensibility, and ease and time of completion. The pilot study showed that the no further revision was needed and thus the DCT was considered a valid and reliable instrument for the study. In addition, the instrument, as well as the research procedures, was also taken to the Research Ethic Committee of 
the Thai university for examination if possible violence of human rights occurred.

\subsection{Data Collection}

The DCT was distributed to the subjects along with the English proficiency test. They were required to take the test for 30 minutes and to fill the questionnaire for another 30 minutes. Prior to that, the researcher provided them with a brief description of the study that included the goals, possible advantages and disadvantages of taking part in the study, and how to do the DCT, and chances for the subjects to inquire about the study. First and foremost, the researcher also asked for their consent to contribute to the study by signing in the consent form upon their agreement and leaving the DCT blank upon their disagreement. During the data collection, the subjects were not allowed to consult a dictionary, books, their communication devices, and friends.

The procedure was first administered with the Thai group which took place in February 2016 and involved 35 out of a 56-student population who came to the appointed places and times and joined the data elicitation. They were then categorized based on their English proficiency test scores that included A2 (20 students), B1 (13 students), and B2 (2 students). Subsequently, the elicitation process was conducted with the Indonesian group. Since the current study aimed to collect data from two equally-competent groups in English and the Indonesian population was much larger, the English proficiency test and the DCT were distributed to unspecified number of students until 35 five subjects with the same distribution of English test scores were found.

\subsection{Coding Scheme}

After the data collection, the CRs were grouped into categories of CR strategy framework proposed Tran (2007). Tran's framework of CR strategies is distinct from other commonly used frameworks in previous studies in that it views CRs not as exclusively separate entities but rather as connected ones that lie in continua. It consists of the Acceptance and Denial Continuum and the Avoidance Continuum. The former consists of Compliment Upgrade (CU), Agreement/Agreement Token (A/AgT), Appreciation Token (ApT), Return (R), Explanation/Comment History (E), Reassignment (Ra), Non-idiomatic Response (NR), Compliment Downgrade (CD), and Disagreement/Disagreement Token (D/DT). On the other hand, the latter is composed of Expressing Gladness, Follow-up Question, (Doubting) Question, and Opting out.

Two possible kinds of responses were initially determined in the data analysis, that were, single responses and multiple responses, which account for the vast majority of the total response. The former contained only one type of CRs while the latter comprised more than one type of CRs. Every type of CRs in one situation was considered as having one CR strategy and thus a response to one complimenting situation could have more than one CR strategy. Multiple responses of the same CR category given to one complimenting situation were counted as one while those falling into different categories were counted as many strategies as the response types.

\subsection{Reliability of Coding}

The coding was done by two coders, the researcher and a native English instructor in the English Department in Naresuan University. In order to ensure the use of the same coding measures, the two coders studied the coding guidelines and had some coding exercises to familiarize themselves with the procedure. Then, the coders worked independently in grouping the data into Tran's continua of CRs. The reliability of the intercoders' coding was measured using Kappa's alpha value to find 'how much better than chance was the agreement between a pair of coders' (Cohen, 1960 cited in Bernard, 2012). Then, the coders had a close examination of the guidelines together and discussed any discrepancy discovered until agreement was reached.

The coding resulted in an unexpectedly high number of discrepancies. As many as 321 responses, from a total of 1666 , were found to be coded differently. There were at least two reasons accounting for this finding, the coder inconsistency and limited categories of CRs in the framework used. In respect to the first situation, the coders met and reviewed the coding guidelines and later revisited the unsatisfactory data. In regard to the difficulty of putting some CRs into any available category, the coders agreed to bring in three new categories, which were Reinterpretation (Ri), Future Reference (FR), and Hope (H). Following these actions, a significant increase in the coding agreement between the coders was reached and it left only 21 unmatched responses, which meant as many as 1645 matches and as high as $98.74 \%$ of agreement level. To test if the agreement between coders was not gained by chance only, the Cohen's Kappa test was applied and resulted in 0.987 score out of 1 , which meant that the data coding had high reliability confidence. Then, the coders further talked over the unmatched responses and also agreed to insert the new categories into the continua. Moreover, feedback from the advisor was also taken into account prior to stating the final coding. The newly modified continua of CRs are presented as follows:

Compliment Upgrade (CU) > Agreement (including Agreement Token) (A) > Hope (H) > Appreciation Token $(\mathrm{ApT})>$ Return $(\mathrm{R})>$ Future Reference $(\mathrm{FR})>$ Explanation $(\mathrm{E})>$ Reassignment $(\mathrm{Ra})>$ Non-idiomatic Response (NR) > Compliment Downgrade CD) > Disagreement (including Disagreement Token) D Figure 1. The Newly Adapted Acceptance to Denial Continuum

Expressing Gladness (EG) > Reinterpretation (Ri) > Further Question (FQ) > Doubting Question (DQ) >
Opting Out (OO)

Figure 2. The Newly Adapted Avoidance Continuum 


\subsection{Data Analysis}

The analysis was done following the research question. At the first part, the analysis explored the frequency of each CR strategy used by each subject group and the group's strategy preference. The results were compared and contrasted to find possible similarities and differences between Indonesian and Thai subjects. A Chi-Square test was applied to examine if significant difference of CR strategy preferences between the two groups existed. Finally, the data were analyzed in regard to the notions of compliment topics (accomplishment/ability, appearance, and possessions).

\section{Results and Discussion}

In this section, the results are presented in two parts according to the research questions: 1) the overall distribution of CRs, and 2) distributions of CRs by compliment topics.

4.1 Research Question 1: How do Indonesian students and Thai students majoring in English respond to compliments in English?

The coding process results in an aggregate of $1666 \mathrm{CR}$ items. They were categorized into 11 strategies of the Acceptance to Denial Continuum and 5 strategies of the Avoidance Continuum. The overall distribution of CR strategies performed by the Indonesian and Thai subject groups is presented in Table 1 below. Then, a quantitative and qualitative analysis of the data follows.

Table 1. The Overall Distributions of CRs in the Two Continua

\begin{tabular}{|c|c|c|c|c|c|c|}
\hline \multirow[b]{2}{*}{$\begin{array}{c}\text { CR } \\
\text { Strategies }\end{array}$} & \multicolumn{3}{|l|}{ Indonesia } & \multicolumn{3}{|l|}{ Thai } \\
\hline & Frequency & $\begin{array}{c}\text { Percentage } \\
(\%)\end{array}$ & $\begin{array}{c}\text { Adjusted } \\
\text { residual }\end{array}$ & Frequency & $\begin{array}{c}\text { Percentage } \\
(\%)\end{array}$ & $\begin{array}{c}\text { Adjusted } \\
\text { residual }\end{array}$ \\
\hline \multicolumn{7}{|c|}{ The Acceptance to Denial Continuum } \\
\hline $\mathrm{CU}$ & 45 & 5.41 & -3.1 & 78 & 9.35 & 3.1 \\
\hline A & 57 & 6.85 & -4.2 & 108 & 12.95 & 4.2 \\
\hline $\mathrm{H}$ & 7 & 0.84 & 2.1 & 1 & 0.12 & -2.1 \\
\hline ApT & 332 & 39.90 & 2.2 & 289 & 34.65 & -2.2 \\
\hline $\mathrm{R}$ & 61 & 7.33 & 0.5 & 56 & 6.71 & -0.5 \\
\hline FR & 12 & 1.44 & -1.4 & 20 & 2.40 & 1.4 \\
\hline $\mathrm{E}$ & 146 & 17.55 & 0.9 & 132 & 15.83 & -0.9 \\
\hline $\mathrm{Ra}$ & 18 & 2.16 & 1.1 & 12 & 1.44 & -1.1 \\
\hline NR & 0 & 0.00 & -1.4 & 2 & 0.24 & 1.4 \\
\hline $\mathrm{CD}$ & 63 & 7.57 & 1.9 & 44 & 5.28 & -1.9 \\
\hline $\mathrm{D}$ & 21 & 2.52 & 2.9 & 6 & 0.72 & -2.9 \\
\hline \multicolumn{7}{|c|}{ The Avoidance Continuum } \\
\hline EG & 9 & 1.08 & -0.7 & 12 & 1.44 & 0.7 \\
\hline $\mathrm{Ri}$ & 7 & 0.84 & -0.9 & 11 & 1.32 & 0.9 \\
\hline FQ & 11 & 1.32 & 0.2 & 10 & 1.20 & -0.2 \\
\hline DQ & 32 & 3.85 & -1.4 & 44 & 5.28 & 1.4 \\
\hline $\mathrm{OO}$ & 11 & 1.32 & 0.5 & 9 & 1.08 & -0.5 \\
\hline Total & 832 & 100.00 & 0 & 834 & 100.00 & 0 \\
\hline
\end{tabular}

Table 1 contains a total of 832 response items made by Indonesians and 834 items by Thais categorized following the two continua adapted from Tran (2007). It shows that Indonesians and Thais made use of a similar range of strategies in both the Acceptance to Denial Continuum and Avoidance Continuum. However, no Non-idiomatic Response was used by Indonesians. The table also displays that Indonesians and Thais used the strategies in varying frequencies. A chisquare test shows that there is a significant relation in the CRs between Indonesians and Thais $(\chi 2=53.378, \mathrm{df}=15$, $p<.001)$. In other words, the two subject groups adopted different strategies of CRs. As the Adjusted Residual test was applied to examine which strategy use contributed to the significant difference between the two groups, the result shows five strategies in the first continuum with Adjusted Residual scores greater than $-/+2$, which means that they have significantly different frequency of use between Indonesians and Thais that include Compliment Upgrade (-3.1 \& 3.1), Agreement (-4.2 \& 4.2), Hope (2.1 \& -2.1), Appreciation Token (2.2 \& -2.2), and Disagreement (2.9 \& - 2.9). In regard 
to the strategies in the Avoidance Continuum, no Adjusted Residual score was noted to exceed $-/+2$ and it means that none of strategy use in this continuum contributes to the significant difference between Indonesians and Thais in responding to compliments.

Following the data presented in Table 1, there are four interesting points that call for further analysis. First, Indonesians and Thais showed different patterns of CRs. Indonesians adopted Compliment Downgrade and Disagreement more than Thais while Thais made more use of Compliment Upgrade and Agreement than Indonesians. To be clearer, Figure 3 below better pictures the opposing patterns of CRs between Indonesians and Thais.

Figure 3 shows that the lines, the dash line depicting Indonesians and the solid line representing Thais, create different patterns at both ends of the continuum. Indonesians seemed to be more positive towards the right end of the continuum, producing higher frequencies in Compliment Downgrade and Disagreement than their Thai counterparts. On the other hand, Thais were seen to be more positive towards the left end of the continuum, generating higher frequencies in Compliment Upgrade and Agreement than Indonesians. It suggests that Indonesians were more prone to deny compliments while Thais had a greater tendency to accept compliments.

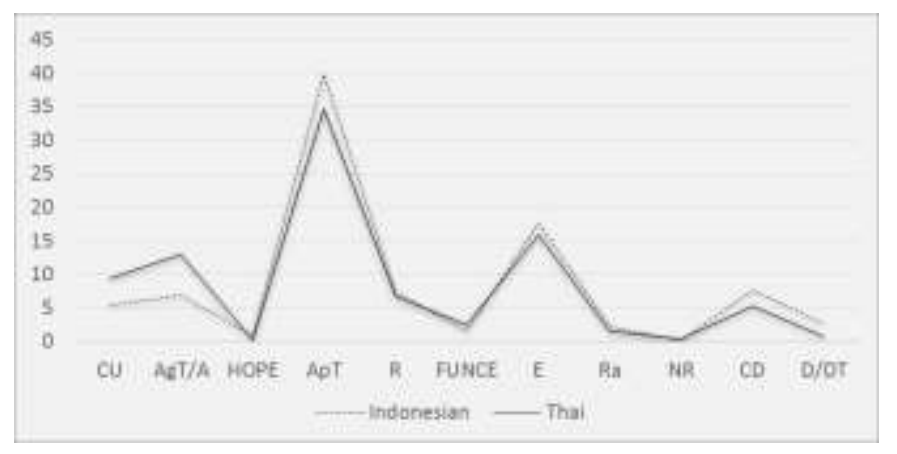

Figure 3. Distributions of CRs in the Acceptance to Denial Continuum

Note. The numerals are the percentages of the total number of responses in each strategy divided by the total number of all numbers in all categories: 832 for Indonesians and 834 for Thais.

Second, Indonesians and Thais clearly had the same inclination towards the most preferred CR strategies in the Acceptance to Denial Continuum for Appreciation Token and Explanation. While explanation is in the middle of the continuum, Appreciation Token lies somewhere closer to the acceptance end of the continuum. Considering that together with other strategies at the left end of the continuum such as Compliment Upgrade, Agreement, and Hope, Appreciation Token accounts for more than half of the total strategy use, this suggests that both groups have higher tendency to show acceptance to compliments than denials. In Tran's (2007) term, both groups have higher degree of agreeing with the complimentary force of the complimenting situations. As displayed in Figure 3, the dash and solid lines are skewed towards both ends of the continuum. The lines rise significantly at the point of Appreciation Token, which lies closer to the left end of the continuum, and mean both groups' inclination towards accepting compliments. In addition, it also implies both groups' positive perception towards compliments.

Meanwhile, the frequent use of Explanation, which lies in the middle of the continua, can be seen as an act of resolving the internal conflict faced by the complimentees. Gajaseni (1994) pointed out that complimentees were often in the internal conflict of whether to be polite by accepting the compliment with the risk of being considered conceited or to avoid self-praise by denying it with the risk of violating the norm of politeness. This is most likely to be true considering that Explanation very often followed strategies at the left end of the continuum such as Agreement and Appreciation Token. Here are examples of the use of Explanation by Indonesians and Thais taken directly from the participants' responses to situations in the DCT without any editing in the language. In the example, $\mathrm{S}$ stands for Situation, P for Participant, and S5P2 for response to Situation 5 by Participant 2.

Examples:

Indonesian (S5P2): Thank you. My dad gave it as my birthday gift. (Appreciation Token - Explanation) Indonesian S2P14: Yes- sure Ma'am/Sir. I'm feeling amazing can celebrated the new year eve in good country. (Agreement-Explanation)

Thai (S5P1): Thank you! My mom bought me on New Year. (Appreciation Token - Explanation)

Thai (S9P2): Yes, it is. I have bought it recently near the swimming pool. (Agreement - Explanation)

Third, despite their high tendency to accept compliments, both Indonesians and Thais also showed some degree of rejections. This may come as a reflection of both groups' native cultures which they referred to when involved in social communication. Thai culture values humility and modesty (Cedar, 2006). Similarly, Indonesians have the same conception about the need of being humble in order to maintain social relationship with others. In this case, the notion of modesty seems to be more apparent in Indonesian data. 


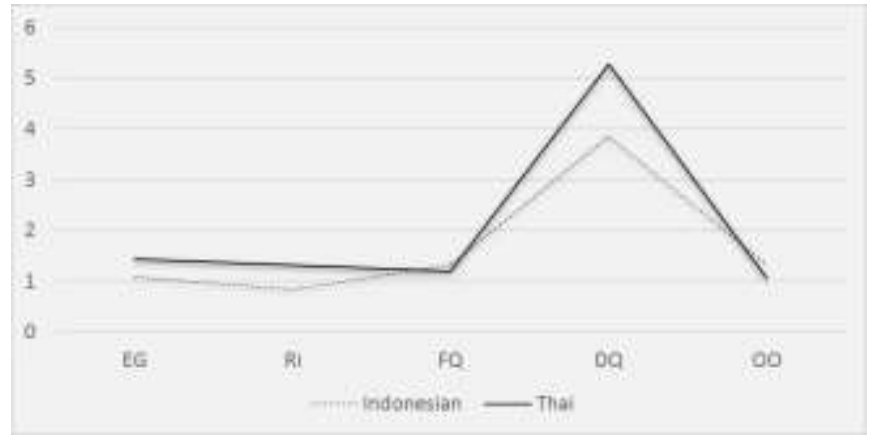

Figure 4. Distributions of CRs in the Avoidance Continuum Note. The numerals are the percentages of the total number of responses in each strategy divided by the total number of all numbers in all categories: 832 for Indonesia and 834 for Thais.

Fourth, regarding the CR strategies in the Avoidance Continuum, Indonesians and Thais opted for Doubting Question as their most preferred strategy. Figure 4 displays that Doubting Question is located near the right end of the continuum, and the two lines increase at the strategy and give more weight to the right end of the continuum. It suggests that both groups were also inclined to avoid compliments. Considering that Thais demonstrated a higher frequency of Doubting Question, it may indicate that Thais tended to avoid compliments more than Indonesians. This tendency seems to be supported by the fact that both groups often made use of the strategy in the same way - at the beginning of multiple responses (See S4P20 and S1P4). The strategy appears to function to maintain modesty in the subjects' responses and to refrain themselves from looking arrogant if they openly accept compliments. Below are some examples of how the strategy was used.

Examples:

Indonesian (S4P20): Really? I have spent my time to prepare all yesterday. Thank you- Sist! You look great too you know. (Doubting Question - Compliment Upgrade - Appreciation Token - Return)

Thai (S1P4): Really? Thank you so much for your compliment and I think I will practice to work in photography for better work in the future. (Doubting Question-Appreciation Token-Future Reference)

4.2 Research Question 2: What are the differences between CR strategies used by the Indonesian students and those used by the Thai students, majoring in English, under the variables of compliment topics?

In addition to investigating how Indonesians and Thais respond to compliments in general, the current study also aimed at examining what strategies they used to respond to compliments on particular compliment topics that include ability/accomplishment, appearance, and possession. This section discusses and explains Indonesian and Thai CRs in relation to the compliment topics.

\subsubsection{Ability/Accomplishment}

Under the ability/accomplishment topic, both Indonesians and Thais seem to give positive response to compliments, although they also used Compliment Downgrade quite frequently. Table 2 shows that Indonesians adopted Appreciation Token as the most preferred strategy, followed by Return and Compliment Upgrade. Similarly, Thais also used Appreciation Token as the most preferred strategy, followed by Compliment Upgrade. This finding is in line with previous studies that both Indonesians and Thais were found to be positive towards compliments on ability/accomplishment. Sari (2009) in her study on the effect of social status and compliment topic found that Indonesians used Appreciation Token in most responses to compliments on ability/accomplishment. Similarly, Chen and Boonkongsaen (2012) claimed that Thais tended to outwardly show more of their pride in their responses on this topic as compared to other topics, and this may explain the fact that Thais adopted more Compliment Upgrade (See S2P24 and S11P5) and Agreement than Indonesians. Meanwhile, considerable use of strategies in the middle of the continuum such as Return (See S11P5 and S7P8) and those at the end such as Compliment Downgrade (S1P25) seem to function to lessen the sense of self-praising and escalating the modesty value of their cultures. It can be seen from the fact that both groups were also likely to combine strategies at the acceptance end of the continuum with those in the middle or even at the end.

Examples:

Indonesian (S1P25): Thanks. Not really- I still 've to learn many things. (Appreciation Token - Compliment Downgrade)

Indonesian (S2P24): Of course sir- because I'm happy spare time with my family on the vacation. (Compliment Upgrade - Explanation)

Thai (S11P5): Thank you very much. I'm very proud of my essay It's good, because of, you teach me. (Appreciation Token - Compliment Upgrade - Return)

Thai (S7P8): Thanks! and you're good at writing too! (Appreciation Token - Return) 
Table 2. Frequency of CR strategies used by Indonesians and Thais to Compliments on Ability/Accomplishment

\begin{tabular}{|c|c|c|c|c|}
\hline \multirow[t]{2}{*}{ CR Strategies } & \multicolumn{2}{|l|}{ Indonesian } & \multicolumn{2}{|l|}{ Thai } \\
\hline & Frequency & Percentage $(\%)$ & Frequency & Percentage $(\%)$ \\
\hline \multicolumn{5}{|c|}{ Acceptance to Denial Continuum } \\
\hline $\mathrm{CU}$ & 26 & 9.45 & 35 & 13.01 \\
\hline AgT/A & 12 & 4.36 & 17 & 6.32 \\
\hline $\mathrm{H}$ & 6 & 2.18 & 0 & 0.00 \\
\hline ApT & 126 & 45.82 & 119 & 44.24 \\
\hline $\mathrm{R}$ & 27 & 9.82 & 16 & 5.95 \\
\hline FR & 12 & 4.36 & 20 & 7.43 \\
\hline $\mathrm{E}$ & 14 & 5.09 & 10 & 3.72 \\
\hline $\mathrm{Ra}$ & 7 & 2.55 & 3 & 1.12 \\
\hline NR & 0 & 0.00 & 0 & 0.00 \\
\hline $\mathrm{CD}$ & 24 & 8.73 & 23 & 8.55 \\
\hline D/DT & 4 & 1.45 & 2 & 0.74 \\
\hline \multicolumn{5}{|c|}{ The Avoidance Continuum } \\
\hline EG & 6 & 2.18 & 9 & 3.35 \\
\hline $\mathrm{Ri}$ & 0 & 0.00 & 1 & 0.37 \\
\hline FQ & 3 & 1.09 & 3 & 1.12 \\
\hline DQ & 4 & 1.45 & 10 & 3.72 \\
\hline $\mathrm{OO}$ & 4 & 1.45 & 1 & 0.37 \\
\hline Total & 275 & 100.00 & 269 & 100.00 \\
\hline
\end{tabular}

In addition, there are two other interesting findings in this study in relation to the compliment topic of ability. First, there is one type of responses that seems to be culture-specific made by Indonesians which does not exist in Thai CRs. Some Indonesians employed Reassignment by referring to God (See S1P18 and S7P28). This seems to reflect Indonesian people who commonly practice their religions strictly. A similar kind of response was also found in the appearance topic CRs. Another interesting finding in this section is the use of new strategies, which did not exist in the continua of CRs (Tran, 2007). While Reinterpretation occurred only once in Thai CRs (See S1P9), Hope and Future Reference were used in considerable frequencies. Hope was used six times by Indonesians only (See S1P2 and S1P5) and Future Reference was used 23 and 20 times by Indonesians and Thais respectively (See S11P9). Hope appears to be an act of accepting compliments indirectly and (or) at the same time showing concern about others' condition as seen in Situation 1 below. On the other hand, Future Reference comes in the form of promises to keep up or improve the complimentee's ability/accomplishment which also reflect modesty and Reinterpretation in the form an offer of things related to the object of compliments. The following are some examples of these strategies.

Examples:

Indonesian (S1P18): “Thank you. God bless me. I still learning like you." (Appreciation Token - Reassignment Compliment Downgrade).

Indonesian (S7P28): A heaps of thanks- I 'just' do the best as I can- and then I let our god decides. (Appreciating Token - Agreement-Reassignment)

Indonesian (S1P2): Oh- thank you. Anyway- thanks for coming. Hope you enjoy it! (Appreciation Token - Opting OutHope)

Indonesian (S1P5): Thanks. I am very happy that works are displayed and have attracted the visitors. I hope that my works in photography can inspiring people. (Appreciation Token - Explanation - Hope)

Thai (S11P9): Thank you for your help and compliment. I will try to practice more. (Appreciation Token - Future Reference)

Thai (S1P9): Thanks. I will take one for you. (Appreciation Token - Reinterpretation)

\subsubsection{Appearance}

Unlike responses on the previous topic, Indonesians and Thais seem to be less positive towards compliments on appearance. As seen in Table 3, both groups used strategies from the middle of the Acceptance to Denial Continuum more frequently, which include Explanation (See S2P4 and S8P18) and Return (S12P13). Despite the subjects' inclination to show appreciation to compliments, compliments on appearance do not seem to represent the norm 
recognized in Indonesian and Thai cultures. This finding is supported by Cedar (2006) who claimed that compliments on appearance do not occur frequently and by Chen and Boonkongsaen (2012) that Thais are sensitive to compliments on appearance so that they make more elaborated responses. This cultural norm is also apparent in both groups' CRs as they not only showed fewer acceptance but also expressed embarrassment in some occasions (See S4P34 and S8P18) and tended to show more avoidance to compliments on appearance by using Doubting Question strategy (See S2P4 and S4P7).

\section{Examples:}

Indonesian (S4P34): Ugh- stop it! It looks bad on me. It's really embarrassing! (Disagreement)

Indonesian (S2P4): Oh- really? Thank you- ma'am. I had a great experience to celebrate a new year eve in Singapore. (Doubting Question - Appreciation Token - Explanation)

Thai (S12P13): Thanks. You look fantastic too. (Appreciation Token - Return)

Thai (S8P18): Yeah, I have new pair of glasses. I'm so shy for new look. (Explanation - Compliment Downgrade)

Thai (S4P7): Oh! Really? Thank you. (Doubting Question - Appreciation Token)

Table 3. Frequency of CR strategies used by Indonesians and Thais to Compliments on Appearance

\begin{tabular}{|c|c|c|c|c|}
\hline \multirow[t]{2}{*}{ CR Strategies } & \multicolumn{2}{|l|}{ Indonesian } & \multicolumn{2}{|l|}{ Thai } \\
\hline & Frequency & Percentage $(\%)$ & Frequency & Percentage $(\%)$ \\
\hline \multicolumn{5}{|c|}{ Acceptance to Denial Continuum } \\
\hline $\mathrm{CU}$ & 12 & 4.35 & 16 & 5.69 \\
\hline AgT/A & 26 & 9.42 & 26 & 9.25 \\
\hline $\mathrm{H}$ & 0 & 0.00 & 1 & 0.36 \\
\hline ApT & 100 & 36.23 & 88 & 31.32 \\
\hline $\mathrm{R}$ & 28 & 10.14 & 33 & 11.74 \\
\hline FR & 0 & 0.00 & 0 & 0.00 \\
\hline$E$ & 64 & 23.19 & 62 & 22.06 \\
\hline $\mathrm{Ra}$ & 7 & 2.54 & 8 & 2.85 \\
\hline NR & 0 & 0.00 & 2 & 0.71 \\
\hline $\mathrm{CD}$ & 7 & 2.54 & 8 & 2.85 \\
\hline D/DT & 2 & 0.72 & 0 & 0.00 \\
\hline \multicolumn{5}{|c|}{ The Avoidance Continuum } \\
\hline EG & 2 & 0.72 & 3 & 1.07 \\
\hline $\mathrm{Ri}$ & 1 & 0.36 & 1 & 0.36 \\
\hline FQ & 4 & 1.45 & 4 & 1.42 \\
\hline DQ & 19 & 6.88 & 22 & 7.83 \\
\hline $\mathrm{OO}$ & 4 & 1.45 & 7 & 2.49 \\
\hline Total & 276 & 100.00 & 281 & 100.00 \\
\hline
\end{tabular}

In addition, a seemingly culture-specific response was also found in CRs on appearance. For example, an Indonesian complimentee reassigned the compliment on appearance as an effect of completing a religious practice (See S8P27). However, this type of response was not found in Thai CRs. Meanwhile, the new strategies were not really used in CRs on appearance. Among the three strategies, only one occurrence of Reinterpretation was found in Indonesian data (See S4P27) and one Hope (See S4P9) and one Reinterpretation (S2P28) in Thai data. In Indonesian data, Reinterpretation was used as the complimentee considered the compliment s/he received flirtatious and responded with an invitation for a date. In Thai data, Reinterpretation occurred when the compliment was interpreted as a request for a souvenir from the complimenter as s/he observed that the complimentee had just come back from vacation while Hope was used by the complimentee likely to thank the complimenter by wishing for the complimenter's wellbeing. Below are the examples of the response specific to Indonesian data and the new strategies.

Example:

Indonesian (S8P27): I've just prayed that's why I look wonderful. (Reassignment)

Indonesian (S4P27): Thanks- you too. Wanna date? (Appreciation Token - Return - Reinterpretation)

Thai (S4P9): Really? Thanks, you look great on this dress too. Hope tonight it's a good day for you. (Doubting Question - Appreciation Token - Return - Hope)

Thai (S2P28): Certainly sir, I was very happy and I have a present for you. (Copmliment Upgrade - Reinterpretation) 


\subsubsection{Possession}

Regarding responses to compliments on possession, Indonesians and Thais were found to have an opposing perception. Indonesians were observed to be more positive towards showing denials while Thais were more likely to show acceptance. Table 4 presents a higher use of strategies at the right end of the Acceptance to Denial Continuum such as Comliment Downgrade and Disagreement by Indonesians and of strategies at the left end of the continuum such as Compliment Upgrade and Agreement by Thais.

Although compliments on possession is not uncommon in Indonesia, accepting compliments on possession can carry the risk of being considered boasting. In relation to possession, people are commonly expected to show humility for it may trigger jealousy and affect social relationships. Therefore, Indonesians in this study seemed to stick to this value by refraining from showing acceptance to compliments and making more use of Explanation (See S5P35) and Compliment Downgrade (See S10P32 and S5P35). In contrast, Thais seemed to lean to accepting compliments. In comparison with compliments on ability where Thais were also inclined to accept compliments, Thais were found to be more positive towards possession. In this situation, Thais adopted more Compliment Upgrade and Agreement (See S9P3 and S9P11) and fewer Compliment Downgrade and Disagreement. This is in contrast with Chen and Boonkongsaen's (2012) claim that Thais were more likely to express pride for ability than possession. In fact, it was found in this study that Thais showed more acceptance to compliments on possession than to those on Accomplishment and Appearance.

Examples:

Indonesian (S10P32): Well thanks- but it was not that expensive. (Appreciation Token - Compliment Downgrade)

Indonesian (S5P35): Thank you- sir/ma'am. It is actually an old one but I try to keep it clean every day. (Appreciation Token - Compliment Downgrade - Explanation)

Thai (S9P3): Thank you. I love too. (Appreciation Token - Agreement)

Thai (S9P11): Yeah. I think so. Thanks a lot. Your is lovely, too. (Agreement-Appreciation Token - Return)

Table 4. Frequency of CR strategies used by Indonesians and Thais to Compliments on Possession

\begin{tabular}{|c|c|c|c|c|}
\hline \multirow[t]{2}{*}{ CR Strategies } & \multicolumn{2}{|l|}{ Indonesian } & \multicolumn{2}{|l|}{ Thai } \\
\hline & Frequency & Percentage $(\%)$ & Frequency & Percentage $(\%)$ \\
\hline \multicolumn{5}{|c|}{ Acceptance to Denial Continuum } \\
\hline $\mathrm{CU}$ & 7 & 2.49 & 27 & 9.51 \\
\hline AgT/A & 19 & 6.76 & 65 & 22.89 \\
\hline $\mathrm{H}$ & 1 & 0.36 & 0 & 0.00 \\
\hline ApT & 106 & 37.72 & 82 & 28.87 \\
\hline $\mathrm{R}$ & 6 & 2.14 & 7 & 2.46 \\
\hline FR & 0 & 0.00 & 0 & 0.00 \\
\hline $\mathrm{E}$ & 68 & 24.20 & 60 & 21.13 \\
\hline $\mathrm{Ra}$ & 4 & 1.42 & 1 & 0.35 \\
\hline NR & 0 & 0.00 & 0 & 0.00 \\
\hline $\mathrm{CD}$ & 32 & 11.39 & 13 & 4.58 \\
\hline $\mathrm{D} / \mathrm{DT}$ & 15 & 5.34 & 4 & 1.41 \\
\hline \multicolumn{5}{|c|}{ Avoidance Continuum } \\
\hline EG & 1 & 0.36 & 0 & 0.00 \\
\hline $\mathrm{Ri}$ & 6 & 2.14 & 9 & 3.17 \\
\hline FQ & 4 & 1.42 & 3 & 1.06 \\
\hline DQ & 9 & 3.20 & 12 & 4.23 \\
\hline $\mathrm{OO}$ & 3 & 1.07 & 1 & 0.35 \\
\hline Total & 281 & 100.00 & 284 & 100.00 \\
\hline
\end{tabular}

In relation to the new strategies, Indonesian and Thai CRs also demonstrated different patterns in this topic. Among the other two strategies, only Reinterpretation received a relatively significant increase in use while others did not. Future Reference and Hope seemed to be not preferred by both groups for there was no use of the former and the latter was used once by an Indonesian. On the other hand, Reinterpretation was found to be used six times by Indonesians and nine times by Thais, respectively, in responding to compliments on possession. Reinterpretation was adopted by the subjects when they perceived the compliments they received as a request for the object or other things related to the object of compliment (See S5P7, S3P6, S10P11, and S5P18). Meanwhile, Hope, which was found in Indonesian data, 
was used to express indirect acceptance and show concern about others' condition (See S5P12). Here are some examples of how the strategy was used.

Examples:

Indonesian (S5P7): No- it is not new. Thank anyway- you could use it when you need to go somewhere else. (Compliment Downgrade - Appreciation Token - Reinterpretation)

Indonesian (S3P6): Thank you. Do you want this watch? I will give you one- because I have a lot. (Apprecation TokenReinterpretation)

Indonesian (S5P12): No- but thank you for your appreciate. I hope you can enjoy your ride with my motorbike. (Disagreement - Appreciation Token - Hope)

Thai (S10P11): Thanks, It's a new collection, do you want to try? (Appreciation Token - Compliment Upgrade Reinterpretation)

Thai (S5P18): Yeah, thank you very much. You can try it if you want. (Agreement - Appreciation Token Reinterpretation)

Overall, the discussion above provides answers to issues raised in this study. Regarding the first question, the current research reveals that Indonesian and Thai subjects had a great tendency to adopt CR strategies at the left end of the Acceptance to Denial Continuum (Figure 3), which also implied their inclination to accept compliments. Moreover, it was also common for both groups to show modesty and humility in their CRs by making use of strategies in the middle or at the end of the continuum, as well as Doubting Question, and by combining them with strategies at the acceptance end. However, the two groups were found to respond to compliments differently. As shown in Figure 3, Indonesians were recorded to adopt CR strategies at the right end of the continuum more than Thais and in constrast Thais made more use of strategies at the left end of the continuum than Indonesians. It implies that Indonesians were more prone to deny compliments than Thais while Thais tended to accept compliments more than Indonesians. In connection with the second question, the study discloses different patterns of CRs between Indonesians and Thais under particular compliment topics. Indonesians were observed to be most positive towards compliments on ability and most negative towards compliments on possession. On the other hand, Thais tended to be most positive towards possession and most negative towards appearance.

In addition, the discussion seems to suggest three aspects of the CRs by Indonesians and Thais that deserve further explanations. First, it is noticeable that Indonesians and Thais were strongly inclined to indicate modesty in their CRs in English. It can be seen from the ways they respond to compliments both in general or under particular topics, i.e. using strategies in the middle and at the right end of the Acceptance to Denial Continuum and Doubting Question and combining them with strategies at the left end of the continuum to attenuate self-praise. This phenomenon can be traced back to the native cultures of the subjects. Indonesia and Thailand are two neighboring countries in the ASEAN region that are well known to have the so-called collectivist culture, which value group concerns greater than individuals' (Watts, 2003; Barron, 2009; Mills, 2011). The people are restricted to avoiding expressing self-pride due to the need of maintaining social harmony. These norms and values are so ingrained in the mind of the people that they are most likely to emerge in how they perform speech acts no matter what the language in use is, e.g. responding to English compliments.

Second, it was previously mentioned that Indonesian and Thai cultures are the same in terms of valuing collecivism. However, culture is a multi-faceted entity and some facets of which may be exclusive to one particular culture and are realized ways that are distinct from one another. In this study, it was found that Indonesians and Thais have different ways of responding to compliments on particular topics and expressing CRs in this study. Regarding the first point, it has been proven in previous studies that each culture has its own belief on what the most appropriate compliment topics are (Chen \& Pochtrager, 1993; Yu, 2005; Allami \& Montazeri, 2012). However, there is another intriguing alternative to account for this phenomenon. Following Leech' politeness theory, it may be suggested that each culture has its own belief on what maxim of politeness to stick to in a particular situation. Under this view, Indonesians tend to apply the agreement maxim to compliments on ability and the modesty maxim to compliments on appearance and possession. On the other hand, Thais seem to prefer the agreement maxim for compliments on ability and possession and the modest maxim for compliments on appearance. In relation to the second point, the phenomenon seems to be triggered by the different norms influenced by the existence of different religions in the two contexts. It has been reported that religious beliefs carry some degree of influences to the linguistic and pragmatic practice of a society, e.g. reference to God (Falasi, 2007). This kind of practice, which is deemed common in the native language of the speakers, is likely to appear in the performance of speech acts in another language, including English by EFL learners.

Third, the current study found three new categories of CRs which did not exist in the two continua of CRs proposed by Tran (2007). These strategies include Hope, Future Reference, and Reinterpretation. These CR strategies were not actually new, for several researchers had also found the use of these strategies in their studies. Ibrahim and Riyanto (2004) reported the occurrence of Hope and Promise in their study on CRs made by Indonesians and Americans in their native languages. That is, in Indonesian CRs on ability, Hope was used by a superior to expect things to work well and Promise was used by an inferior to express commitment to do better in the future. Suh (2010) also reported the use of Promise by Koreans in CRs on character to offer assistance again in the future. In relation to Reinterpretation, Falasi (2007), Allami \& Montazeri (2012), An (2013), and Monjezi (2014) reported the use of Reinterpretation by their research subjects when they interpreted compliments on possession as requests and responded by offering the objects or things related to the objects of compliments. 


\section{Conclusion}

In conclusion, the findings of this study confirm findings of previous studies that there is a connection between language and culture. Language and culture are intricately related to each other to a certain extent that they are somehow inseparable. Culture is often, if not always, reflected in the language one speaks or in how they speak a language. No matter how close two cultures literally are, differences are unavoidable and they are most likely to emerge in the language members of the two cultures use in communication, such as English.

Indonesia and Thai are two different countries believed to share a number of cultural characteristics in common, especially in terms of valuing collectivism among the people. Nonetheless, the study demonstrates significant differences in responding to English compliments between Indonesian and Thai subjects. Indonesians were found to have a greater tendency to show denials to compliments while Thais are more prone to express acceptance. Indonesian and Thai subjects also seem to have different preference on compliment topics. Indonesians are most positive towards compliments on ability and most negative towards those on possession. On the other hand, Thais are most positive towards compliments on possession and most negative towards those on appearance. Moreover, Indonesians also respond to compliments in a particular way that is not used by Thais.

This study is important to help raising EFL learners' awareness of the fact that one language, e.g. English, can be used differently by people from different cultures and of the importance of having knowledge of other cultures' communication practice so that they can later be a competent communicator in intercultural communication. It also important in terms of revealing the practice of English CRs of Indonesians and Thais to EFL learners from both Indonesia and Thailand and other parties in contact with the two cultural groups or learning about the two cultures to promote better understanding. Lastly, this study comes as an enrichment to the literature for further studies in the relevant areas.

In addition, the study offers two kinds of implication: methodological and pedagogical. Methodologically, the current research suggests that particular subjects and data collection instrument may generate unique responses to compliments which no available framework of analysis can perfectly fit. Therefore, it is advisable for researchers working on CRs, and similar topics, not only to adopt a particular framework of analysis, but also make some adaptation so that better analysis and results can be drawn. In terms of pedagogy, the study suggests that, if the goal of ELT is to produce learners with competence as close to native speakers as possible, the current ELT practice in both cultures needs to give more attention to the teaching of pragmatic convention of English native speakers so learners can set aside or reduce the influence of their native cultures in their use of English. However, it is also pivotal for English teachers not to neglect the fact that English has become the major language in the world with non-native speakers as the majority.

Despite its fruitful contributions, the current study also suffers several limitations. First, the study involved small groups of Indonesian and Thai subjects and therefore the findings cannot be adequately generalized to all Indonesians and Thais. Second, the data in the study was collected using a set of DCT questionnaire, which has been criticized by scholars for failing to elicit data in real use, regardless of its advantages. It is suggested for researchers in future studies to employ more than one data collection instrument so more aspects of language use can be discovered. Lastly, it is no secret that one of the main problems in pragmatic studies is the difficulty of assigning data into categories. Often, one expression is coded into different categories by different researchers or in different framework. Hence, it is expected that researchers propose a better-enhanced framework that can apply more universally and brings better consistency in the data analysis in future studies.

\section{References}

Allami, H., \& Montazeri, M. (2012). A Sociopragmatic Analysis of Compliment Responses in Persian. Iranian Journal of Applied Language Studies, 4(1), 1-38.

Bardovi-Harlig, K. (2010). Exploring the pragmatics of interlanguage pragmatics: Definition by design. Pragmatics across languages and cultures, 7, 219-259.

Barron, A. (2008). Contrasting requests in Inner Circle Englishes: A study in variational pragmatics. Developing contrastive pragmatics: Interlanguage and cross-cultural perspectives, 355-402.

Bernard, H. R. (2012). Social Research Methods: Qualitative and Quantitative Approaches. (2 ${ }^{\text {nd }}$ ed.). SAGE Publications.

Boonkongsaen, N. (2011). Filipino and Thai Responses to Compliments in English. Naresuan University Journal, 19(1), 49-55.

Bowe, H. J., \& Martin, K. (2014). Communication across cultures: mutual understanding in a global world. Cambridge: Cambridge University Press.

Cedar, P. (2006). Thai and American responses to compliments in English. The Linguistics Journal, 1(2), 6-28.

Chen, Y.-s., \& Rau, D. V. (2011). Investigating the complimenting behaviors of Chinese speakers of American English. Language and Linguistics, 12(4), 917-950.

Chiang, B., \& Pochtrager, F. (1993). A Pilot Study of Compliment Responses of American-Born English Speakers and Chinese-Born English Speakers. (ERIC_NO: ED356649). 
Crystal, D. (2003). English As a Global Language. Cambridge, UK: Cambridge University Press.

Dippold, D. (2008). Reframing one's experience: Face, identity and roles in L2 argumentative discourse. Developing contrastive pragmatics: Interlanguage and cross-cultural perspectives, 131-153.

Falasi, H. (2007). Just say thank you: A study of compliment responses. The Linguistics Journal, 2(1), 28-42.

Félix-Brasdefer, J. C. (2010). Data collection methods in speech act performance. Speech act performance: Theoretical, empirical and methodological issues, 26, 41.

Gajaseni, C (1994). How Americans and Thais respond to compliments. Paper presented at the annual meeting of the International Conference on Pragmatics and Language Learning. Urbana, IL, Retrieved from http://www.eric.ed.gov/PDFS/ED378840.pdf

Golato, A. (2002). German compliment responses. Journal of Pragmatics, 34(5), 547-571.

Golato, A. (2005). Compliments and compliment responses: Grammatical structure and sequential organization (Vol. 15): John Benjamins Publishing.

Herbert, R. K. (1989). The ethnography of English compliments and compliment responses: A contrastive sketch. Contrastive pragmatics, 3-35.

Hobbs, P. (2003). The medium is the message: Politeness strategies in men's and women's voice mail messages. Journal of Pragmatics, 35(2), 243-262.

Ibrahim, J., \& Riyanto, T. J. (2004). A sociolinguistic study of compliment responses among Americans and Indonesians and its implications for teaching English. $k @ t a, 2(1), 21-30$.

Katsuta, H. (2012). The Role of Compliment Topics in Compliment Response. Doctoral dissertation, Portland State University. (1529750)

Knutson, T. J. (2004). Thai cultural values: Smiles and sawasdee as implications for intercultural communication effectiveness. Journal of Intercultural Communication Research, 33(3), 147-157.

Leech, G. N. (2014). The pragmatics of politeness. Oxford: Oxford University Press.

Lewandowska-Tomaszczyk, B. (1989). Praising and complimenting. Contrastive pragmatics, 73-100.

Lorenzo-Dus, N. (2001). Compliment responses among British and Spanish university students: A contrastive study. Journal of Pragmatics, 33(1), 107-127.

Mills, S. (2011). Discursive approaches to politeness and impoliteness. Discursive approaches to politeness, 8, 19.

Novera, I. A. (2004). Indonesian Postgraduate Students Studying in Australia: An Examination of Their Academic, Social and Cultural Experiences. International Education Journal, 5(4), 475-487.

Rovinelli, R. J., \& Hambleton, R. K. (1976). On the use of content specialists in the assessment of criterion-referenced test item validity. Dutch Journal of Educational Research, 2, 49-60.

Sari, Y. (2009). Compliment Responses Used by Indonesians Learning English Based on the Compliment Topics and Social Statuses. SKRIPSI Jurusan Sastra Inggris-Fakultas Sastra UM. Unpublished Bachelor Degree thesis.

Schauer, G. A. (2009). Interlanguage Pragmatic Development: The Study Abroad Context. London: Continuum.

Senft, G. (2009). Phatic communion. Culture and language use, 2, 226-233.

Thomas, J. (1983). Cross-Cultural Pragmatic Failure. Applied linguistics, 4(2), 91-112.

Tran, G. Q. (2007). Compliment response continuum hypothesis. Language Society and Culture, 21.

Watts, R. J. (2003). Politeness. Cambridge: Cambridge University Press.

Yu, M.-c. (2005). Sociolinguistic competence in the complimenting act of native Chinese and American English speakers: A mirror of cultural value. Language and speech, 48(1), 91-119. 